\title{
Impact Modified Polyvinyl Chloride Based Thermoplastic Elastomers: Effect of Nitrile Butadiene Rubber and Graphene Oxide Loading
}

\author{
Kuhanraj Vijayan, Mathialagan Muniyadi* and Yamuna Munusamy \\ Department of Petrochemical Engineering, Faculty of Engineering and Green \\ Technology, Universiti Tunku Abdul Rahman, Perak Campus, Jalan Universiti, \\ Bandar Barat, 31900 Kampar, Perak, Malaysia. \\ *Corresponding author: mathialagan@utar.edu.my
}

Published online: 31 May 2021

To cite this article: Kuhanraj Vijayan, Mathialagan Muniyadi and Yamuna Munusamy (2021). Impact modified polyvinyl chloride based thermoplastic elastomers: Effect of nitrile butadiene rubber and graphene oxide loading. Journal of Engineering Science, 17(1), 51-74, https://doi.org/10.21315/jes2021.17.1.4.

To link to this article: https://doi.org/10.21315/jes2021.17.1.4

\begin{abstract}
A new thermoplastic elastomer with improved impact and tensile properties was produced through melt blending of graphene oxide filled nitrile butadiene rubber (NBR-GO) and polyvinyl chloride $(P V C)$ without the addition of plasticisers and thermal stabilisers. Nitrile butadiene rubber (NBR) compounds, with and without graphene oxide (GO) are prepared through latex compounding method and cured, prior to blending with PVC. The effect of NBR and NBR-GO loading on the process-ability and physico-mechanical properties of PVC blends were evaluated. The addition of NBR and NBR-GO improved tensile strength (TS), impact strength and swelling resistance of PVC. Addition of NBR also increased the stiffness of PVC due to higher elasticity of NBR as compared to PVC. Optimum impact strength, TS and swelling resistance was achieved with the addition of 10 wt. \% NBR-GO. Good miscibility between NBR and PVC, and additional reinforcement by $G O$ is responsible for enhancement of impact and TS. NBR-GO showed greater miscibility in PVC as compared to NBR as proven by morphological observation under scanning electron microscope. Morphological observation reveals that micro-cracks formation on PVC/3ONBR surface which is responsible for low impact, tensile and swelling properties as compared to PVC/3ONBR-GO composite.
\end{abstract}

Keywords: polyvinyl chloride, nitrile butadiene rubber, graphene oxide, thermoplastic elastomers, latex compounding 


\section{INTRODUCTION}

Graphene oxide (GO) has gained a huge interest as an advanced material among researchers due to its inherent properties such as high surface to volume ratio contributed by the two-dimensional, single layered carbon structure and fully exfoliated GO sheets of large specific surface area. Besides, GO is 200 times stronger than steel and exhibits high thermo-mechanical properties as well as excellent tensile properties and electrical conductivity as compared to many other materials such as carbon nanotubes (CNTs), carbon and Kevlar fibres. GO is oilindependent and can be readily produced from any types of graphene or graphite through Hummers method which is very economical. ${ }^{1-3}$

Based on these exceptional and unique properties, graphene and its derivatives has found its applications in various field such as field effect devices, sensors, electrodes, solar cells, energy storage devices and nanocomposites. Utilisation of GO in polymer mainly focused on improving the electrical, mechanical, thermal and gas barrier properties. Some studies show that addition of 1 vol. \% graphene into insulative polymers such as polystyrene would improve the conductivity to approximately $0.1 \mathrm{Sm}^{-1}$ and enhances the strength, fracture toughness and fatigue strength of polystyrene. ${ }^{4-6}$ However, limited research has been reported on the effect of intrinsic structure-properties relationship of graphene and its derivatives in polymer nanocomposites.

Several researches have been reported on the successful development of graphene filled polymer nanocomposites through in-situ polymerisation, melt mixing and solution blending. In-situ polymerisation is the most suitable method to produce graphene filled polymer nanocomposites. ${ }^{7}$ Graphene particles are dispersed in neat monomers followed by the polymerisation in the presence of graphene dispersion. The mixture is then precipitated/extracted or cast to produce the nanocomposites. This technique allows high level of dispersion of graphene without prior exfoliation. However, the disadvantage of in-situ polymerisation is that only the graphite nanoplatelets (GNPs) are exfoliated whereas the single layer graphene was not observed under transmission electron microscope (TEM). Study by Fim et al. ${ }^{7}$ reported that graphene platelets can only be dispersed into a $3.6 \mathrm{~nm}$ thickness sheets in polyethylene matrix which possess relatively low aspect ratio of about 30 . Nanocomposites with covalent crosslink between the matrix and graphene can be produced through in-situ polymerisation. Besides, variety of non-covalent nanocomposites can also be developed through in-situ polymerisation by using polymers such as polyethylene, polymethyl methacrylate (PMMA) and polypyrrole. ${ }^{8,9}$ 
Meanwhile, melt mixing was developed to minimise the usage of chemical solvents and is often believed to be the most cost-effective mixing method which allows good filler dispersion under high shear force. However, melt mixing is not effective in dispersing graphene sheets as compared to solution blending or in-situ polymerisation due to the increased polymer viscosity at high graphene loading. Besides, graphene tends to absorb and store the heat supplied for the melting of polymer resins which delays the melting of polymer and increases the mixing torque of polymer melt. Various graphene-based nanocomposites such as exfoliated graphite-PMMA, graphene-polypropylene (PP), GO-poly (ethylene2,6-naphthalate) (PEN) and graphene-polycarbonate was successfully produced through melt mixing. ${ }^{10-13}$

Graphene filled polymer composites including polystyrene, ${ }^{14}$ polyacrylamide, polyimides ${ }^{15}$ and PMMA $^{16}$ was produced through solution blending. It was reviewed by Wang et al. that solution blending offers a promising approach in dispersing GO platelets into polymer matrix and to achieve a stable GO platelet suspension in polymer matrix as compared to melt mixing and in-situ polymerisation. ${ }^{14}$ Thus, in this study GO was first dispersed in NBR in latex form through latex compounding and cured in order to produce NBR-GO in solid form. The cured NBR-GO was then used in preparing NBR-GO filled polyvinyl chloride (PVC/NBR-GO) composites.

Studies on blending polymers have been initiated as early as in 1980 s which is mainly intended to improve properties and for economic advantages of polymer product industries. One of the most commercially important and efficiently process-able polymer blends is that of NBR and PVC. ${ }^{17}$ Both NBR and PVC are used to overcome the limitation cause by each of these materials when used separately. Thou the global consumption rate is increased annually; utilisation of PVC is limited to mostly general-purpose applications due to its low mechanical and thermal stability. Besides, the rigid nature of PVC requires the addition of plasticisers to facilitate the processing and shaping of PVC which is not economical. Thus, NBR addition would act as permanent plasticiser and diversify the usage of PVC in applications such as in wire and cable insulation, food packaging and containers, pond liners used for oil containment and etc which requires PVC to be flexible and easy to be shaped.

On the other hand, usage of NBR is limited to applications that requires high oil resistance and high tear and wear properties. Blending PVC and NBR improves the ozone, thermal aging and chemical resistance of NBR to be used in application such as feed hose covers, gaskets, conveyor belt covers, printing roll covers and etc. Besides, PVC also further improves the abrasion resistance, tear resistance and TS of NBR. ${ }^{18}$ 
Development of PVC/NBR blends have been reported earlier and gaining more interest among researchers all around the world due to the feasibility in processing $\mathrm{PVC} / \mathrm{NBR}$ blends through conventional milling, extrusion or compression moulding using traditional processing equipment for natural and synthetic rubber. ${ }^{19} \mathrm{PVC}$ and NBR are highly miscible to form a soft blend which can be categorised as a thermoplastic elastomer (TPE). However, the difficulty in producing a successful blend of NBR and PVC is due to the lack of suitable thermal stabiliser for PVC which does not affect the properties of PVC/NBR. Barium stearate and cadmium stearate combination is the most used stabiliser which does not obviously deteriorates the physical properties of PVC/NBR blends, yet it does produce yellowish tint and patches which limits the colour flexibility of the blends. ${ }^{20}$

Wimolmala, Wootthikanokkhan and Sombatsompop ${ }^{21}$ reported on the blending of PVC and NBR at different composition (5 wt. \% to $40 \mathrm{wt} . \%$ of rubber) using a Brabender plasticoder. Results showed that the ultimate TS and modulus of PVC/NBR blend were found to be decreased with the increasing NBR content due to phase separation between PVC and NBR. However, the optimum tensile toughness was obtained at $30 \mathrm{wt}$ \% NBR. In another study, Wong and Wootthikanokkhan ${ }^{22}$ reported that the miscibility of PVC and NBR blend produced using twin screw extruder was decreased with increasing NBR content. NBR particles tend to form agglomeration and phase separation occurs, subsequently reduces the miscibility and properties of PVC/NBR blends. Meanwhile, Khalaf et al. ${ }^{23}$ studied the effect of blending different types of rubber with PVC and found that PVC/NBR blends possess excellent engine and hydraulic oils resistance.

The present work is aiming to elaborate the production of PVC/NBR blends through melt mixing without the use of plasticiser or thermal stabilisers. This work is a two-step process which involves the production of NBR and NBRGO through latex compounding. There is no research work reported on two step preparation of PVC/NBR composites especially that involves NBR in latex form. Earlier researches involve melt mixing of PVC and NBR in dry form with the addition of plasticisers and thermal stabilisers which can be very costly due to high price of plasticisers and thermal stabilisers. Besides, latex compounding of NBR can be classified as solution blending which allows good dispersion of GO particles in NBR latex for high end properties and applications. GO is used as to facilitate the processing as well as to improve the mechanical and thermal properties of PVC/NBR blends. The second step involves the melt mixing of PVC and NBR or NBR-GO at different composition using a Brabender internal mixer. The effects of NBR and NBR-GO loading on the processing torque, tensile properties, impact strength, swelling resistance and morphological properties was studied. 


\section{EXPERIMENTAL DETAILS}

\subsection{Materials}

PVC in powder form were purchased from Chemical Solutions Ltd., Selangor, Malaysia while NBR in latex form was purchased from Synthomer Sdn. Bhd., Johor, Malaysia. NBR latex supplied contains total solid content (TSC) of 44.8\%, viscosity of $23 \mathrm{mPa}$ and $\mathrm{pH}$ is 8 . GO was supplied by Platinum Green Chemicals Sdn. Bhd., Negeri Sembilan, Malaysia, in paste form containing 15 wt. \% GO particles. Bis (2-Ethylhexyl) phthalate (DOP) and stearic acid was supplied by Zarm Scientific and Supplies Sdn. Bhd., Pulau Pinang, Malaysia.

\subsection{NBR and NBR-GO Preparation}

NBR latex compounding with and without $1 \mathrm{wt}$. \% GO was compounded through latex compounding method. All the compounding ingredients used in the compounding of NBR and NBR-GO are listed in Table 1. The compounding was carried out by sieving the adequate amount of NBR latex using a wire mesh to remove any impurities. Potassium hydroxide $(\mathrm{KOH})$ was added into latex and stirred using an overhead mechanical stirrer at $300 \mathrm{rpm}$. For NBR-GO, 1 wt. \% $\mathrm{GO}$ was added after $\mathrm{KOH}$ addition and the mixture was left under stirring for 30 min. All the other ingredients except sulphur were then added into the mixture and left to mix for another $30 \mathrm{~min}$. Finally, sulphur was added and the mixing was continued for another $30 \mathrm{~min}$ at $600 \mathrm{rpm}$. Upon the completion of mixing, compound was transferred into steel tray and cured in oven at $100^{\circ} \mathrm{C}$ for $24 \mathrm{~h}$. The dried NBR and NBR-GO compounds were then cut into smaller pieces.

Table 1: Compounding formulation of NBR and NBR-GO.

\begin{tabular}{lccc}
\hline \multirow{2}{*}{ Ingredient } & \multirow{2}{*}{ TSC (\%) } & \multicolumn{2}{c}{ Dry weight (phr) } \\
\cline { 3 - 4 } & & NBR & NBR-GO \\
\hline NBR & 43.9 & 100 & 100 \\
KOH & 10.0 & 1.0 & 1.0 \\
GO & 15.0 & 0.0 & 1.0 \\
Zinc diethyl dithiocarbamate (ZDEC) & 49.5 & 1.0 & 1.0 \\
Zinc 2-mercaptobenzothiazole (ZMBT) & 50.0 & 0.5 & 0.5 \\
Zinc oxide (ZNO) & 45.6 & 1.0 & 1.0 \\
Sulphur & 44.0 & 1.0 & 1.0 \\
\hline
\end{tabular}




\subsection{Melt Blending of PVC/NBR and PVC/NBR-GO}

The composites were produced through melt mixing of PVC and NBR or NBRGO by using Rheometer Brabender ${ }^{\circledR}$ Plastograph ${ }^{\circledR}$ EC 815652 (Brabender $\mathrm{GmbH} \&$ Co. KG, Duisburg, Germany). Mixing was carried out at $180^{\circ} \mathrm{C}$ for $8 \mathrm{~min}$ at $60 \mathrm{rpm}$. The compounding formulation of PVC, PVC/NBR and PVC/NBR-GO composites are as shown in Table 2. NBR and NBR-GO content used was 10 wt. $\%$ and $30 \mathrm{wt}$. \% which was adopted from studied reported by Wimolmala, Wootthikanokkhan and Sombatsompop ${ }^{21}$ which suggest that optimum NBR content in PVC/NBR blending is $30 \mathrm{wt}$. \%. Processing torque generated upon blending of PVC and NBR was recorded. PVC, PVC/NBR and $\mathrm{PVC} / \mathrm{NBR}-\mathrm{GO}$ composites were then pressed into $0.5 \mathrm{~mm}$ thickness sheets using a hydraulic hot and cold press machine (GT-7014-A30C from GT Instruments Sdn. Bhd., Malaysia) at $180^{\circ} \mathrm{C}$. The composites were preheated for $5 \mathrm{~min}$ and hot pressed for $5 \mathrm{~min}$, followed by cool press for $3 \mathrm{~min}$. The produced sheets were then cut into testing specimens.

Table 2. Compounding formulation of PVC, PVC/NBR and PVC/NBR-GO composites.

\begin{tabular}{lccccc}
\hline \multirow{2}{*}{ Ingredients } & \multicolumn{5}{c}{ Composites/composition (wt. \%) } \\
\cline { 2 - 6 } & PVC & PVC/10NBR & PVC/30NBR & PVC/10 NBR-GO & PVC/30NBR-GO \\
\hline PVC & 100 & 90 & 70 & 90 & 70 \\
DOP & 30 & - & - & - & - \\
Stearic acid & 3.0 & - & - & - & - \\
NBR & - & 10 & 30 & - & - \\
NBR-GO & - & - & - & 10 & 30 \\
\hline
\end{tabular}

\subsection{Characterisation and Testing}

\subsubsection{Fourier transform infra-red (FTIR) analysis}

FTIR analysis was carried out using Perkin Elmer Spectrum ex1 (Perkin Elmer, United States) to identify the types of functional groups exist in GO, PVC, PVC/ NBR and PVC/NBR-GO composites. The analysis was carried out to determine the absorption band with a wavelength from $4,000 \mathrm{~cm}^{-1}$ to $400 \mathrm{~cm}^{-1}$ with 4 scans at a resolution of $4 \mathrm{~cm}^{-1}$.

\subsubsection{Swelling test}

PVC, PVC/NBR and PVC/NBR-GO specimens were prepared by cutting the compressed sheets into dumbbell shaped samples using a dumb-bell cutter. 
Toluene was used as solvent and test was conducted accordance with ASTM D471-79. The test pieces were weighed using an electronic balance and initial mass $\left(\mathrm{M}_{0}\right)$ were recorded. The test pieces were then soaked in toluene for $72 \mathrm{~h}$ at room temperature and stored in dark place. After $72 \mathrm{~h}$, the test pieces were weighed again and the mass of the specimens after immersion $\left(\mathrm{M}_{\mathrm{i}}\right)$ were recorded. Swelling percentage which is the indication of swelling resistance of the samples in toluene was calculated by using Equation 1. The higher swelling percentage indicates the low swelling resistance of the sample.

$$
\text { Swelling percentage }=\frac{\left(M_{i}-M_{0}\right)}{M_{i}} \times 100 \%
$$

\subsubsection{Tensile test}

Tensile test was conducted according to ASTM D638 standard on dumbbell-shaped specimens. Tensile test was carried out under ambient condition to measure the tensile modulus, ultimate TS and elongation at break (Eb) of PVC, PVC/NBR and PVC/NBR-GO at different NBR and NBR/GO loading. The test was conducted using Tinius Olsen H10KS-0748 (Leader Technology Scientific (M) Sdn. Bhd., Malaysia) with a load cell of $500 \mathrm{~N}$, at a crosshead speed of $50 \mathrm{~mm} \mathrm{~min}^{-1}$.

\subsubsection{Impact test}

Izod impact test was carried out according to ASTM D256 standard on notched composite samples. The sample dimensions were fixed to $64 \mathrm{~mm} \times 12.7 \mathrm{~mm} \times$ $3.2 \mathrm{~mm}(1 \times \mathrm{w} \times \mathrm{t})$. Zwick impact test was used to measure the total impact energy (joule) required in fracturing a standard test specimen. The impact loads of $7.5 \mathrm{~J}$ and $15.0 \mathrm{~J}$ were used to determine the impact energy which was used to calculate the impact strength of the composites using Equation 2.

$$
\text { Impact strength }=\frac{\text { Impact energy }}{\text { Cross sectional area of specimen }}
$$

\subsubsection{Morphological analysis}

The morphological observation of tensile fractured surface of PVC, PVC/NBR and PVC/NBR-GO composites were carried out using scanning electron microscope (SEM) model: JOEL JSM 6701F (JOEL, USA. Inc., United States of America) at accelerating voltage of $2 \mathrm{kV}$. Prior to examination, the specimens were placed on a disc and held in place using a double-sided carbon tape and then coated with platinum to reduce the electron charging upon observation. 


\section{RESULTS AND DISCUSSION}

\subsection{Processing Torque}

Figure 1 shows the stabilisation torque for melt mixing of $\mathrm{PVC}, \mathrm{PVC} / \mathrm{NBR}$ and PVC-NBR/GO composites. Typically, mixing torque can be used as an indication of viscosity, stiffness and process-ability of the mixing compounds. Whereas stabilisation torque indicates the final torque recorded upon accomplishing the homogeneous mixture of a polymer blend. High torque readings indicate high viscosity and stiffness of composites which makes the melt mixing of polymer very difficult. Stabilisation torque reading of PVC/NBR and PVC/NBR-GO are slightly higher as compared to PVC. Addition of NBR increased the stiffness of PVC due to the elastic and tough nature of NBR which subsequently increased the torque required to homogeneously mix PVC and NBR. However, the presence of 1 wt. \% GO in PVC/NBR-GO have reduced the torque required to mix PVC and $\mathrm{NBR}$ as can be seen from the lower torque values of PVC/NBR-GO as compared to PVC/NBR. Addition of GO into NBR facilitates the processing of PVC/NBR composite. This could be due to the presence of GO particles in NBR which reduced the elasticity of NBR-GO and helped on better dispersion of NBR-GO in PVC as compared to NBR. NBR is highly elastic material due to its elastomeric in nature as compared to GO particles which is rigid. Thus addition of GO particles tends to reduce the elasticity of NBR. The reduced elasticity of NBR-GO reduces the shear between the NBR-GO phase and PVC thus enhancing the dispersion of NBR-GO in PVC as compared to neat NBR.

\section{$3.2 \quad$ FTIR}

FTIR analysis was conducted on raw GO, PVC, PVC/NBR composites and PVC/ NBR-GO composites in order to determine the functional groups in raw materials and the possible chemical interaction between PVC, NBR and GO. Figure 2 shows the infrared (IR) spectra of GO for the scanning range of $400 \mathrm{~cm}^{-1}$ to $4,000 \mathrm{~cm}^{-1}$. The first significant absorption peak was observed at $1,221 \mathrm{~cm}^{-1}$ corresponding to the vibration of $\mathrm{C}-\mathrm{O}$ bonds. Absorption peak at $1,588 \mathrm{~cm}^{-1}$ shows the presence of unoxidised $\mathrm{sp}^{2} \mathrm{C}=\mathrm{C}$ bonds in GO. The next peak at $1,710 \mathrm{~cm}^{-1}$ represents the stretching vibration of $\mathrm{C}=\mathrm{O}$ bonds and peak at $3,369 \mathrm{~cm}^{-1}$ corresponds to the stretching vibration of hydroxyl $(\mathrm{OH})$ groups. ${ }^{24}$ 


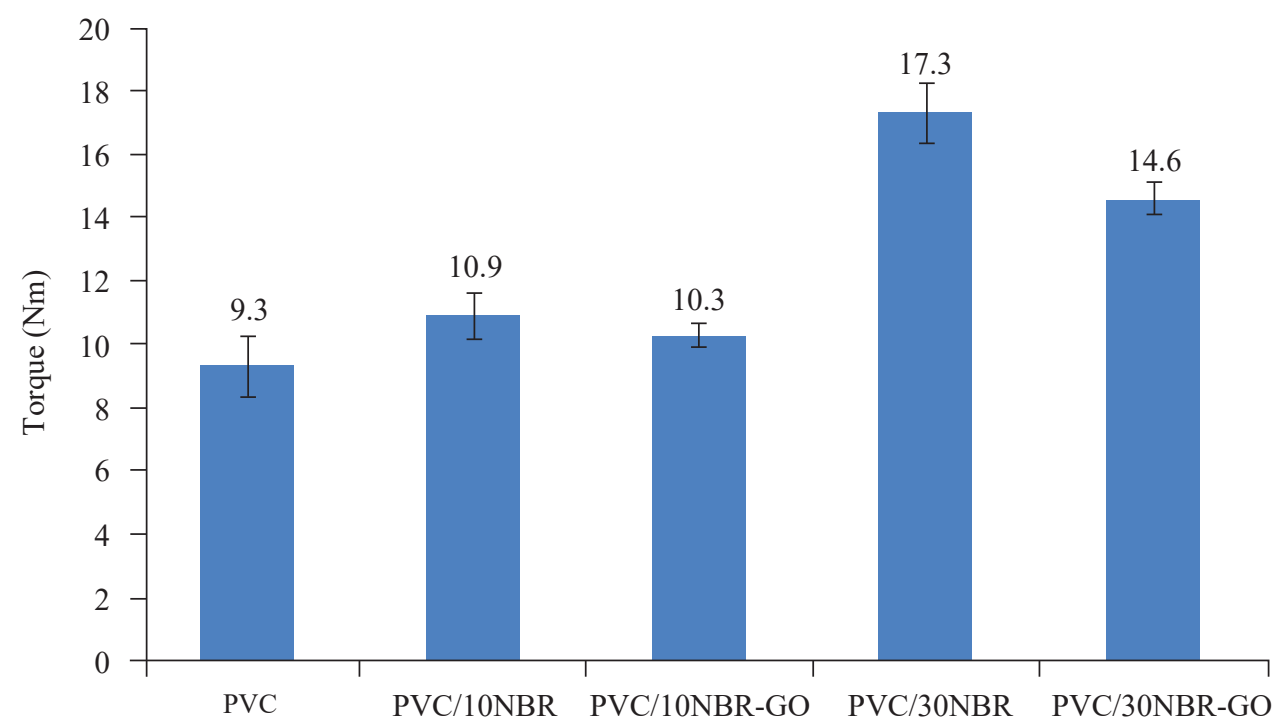

Figure 1: Processing torque as function of NBR and NBR-GO loading.

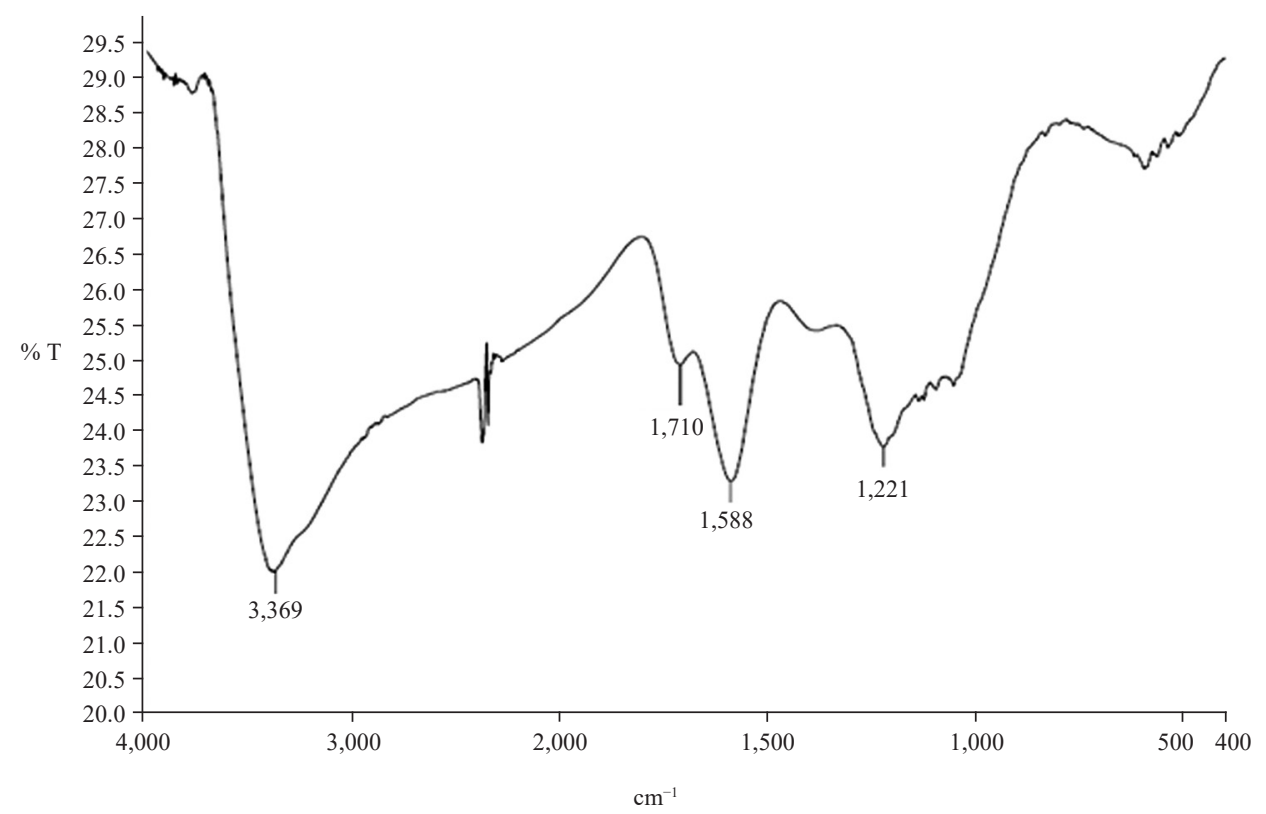

Figure 2: IR spectra of GO. 
The functional groups present in $\mathrm{PVC}$ and $\mathrm{PVC} / \mathrm{NBR}$ composites can be determined by analysing the IR spectra as shown in Figure 3. The presence and increasing peak intensity corresponding to the nitrile group near $2,215 \mathrm{~cm}^{-1}$ confirmed the presence of nitrile rubber in PVC composites. As depicted from Figure 3(a), the absorption peaks at $3,725 \mathrm{~cm}^{-1}, 3,515 \mathrm{~cm}^{-1}$, the broad band between $2,800 \mathrm{~cm}^{-1}$ to $3,000 \mathrm{~cm}^{-1}$, peak at $1,845 \mathrm{~cm}^{-1}$, the broad band between $1,650 \mathrm{~cm}^{-1}$ to $1,800 \mathrm{~cm}^{-1}, 1,542 \mathrm{~cm}^{-1}$ and the peak at $616 \mathrm{~cm}^{-1}$ all corresponds to the functional groups in PVC. Whereas, addition of $10 \mathrm{wt} . \%$ and $30 \mathrm{wt}$. \% of NBR as shown in Figures 3(b) and 3(c), respectively clearly indicate the increasing in intensity of peaks at $2,215 \mathrm{~cm}^{-1}$. The peak at $2,215 \mathrm{~cm}^{-1}$ indicates the increasing in nitrile groups in PVC with the increasing NBR loading.

Meanwhile, the peak at $3,725 \mathrm{~cm}^{-1}$ and $3,515 \mathrm{~cm}^{-1}$ represents the $\mathrm{O}-\mathrm{H}$ stretching of absorbed moisture in PVC. Broad absorption band between $2,800 \mathrm{~cm}^{-1}$ to $3,000 \mathrm{~cm}^{-1}$ correspond to the $\mathrm{C}-\mathrm{H}$ bond stretching by which the higher wave indicates the asymmetric stretch of $\mathrm{C}-\mathrm{H}$ bond whereas, the lower wave represents the symmetric stretch of $\mathrm{C}-\mathrm{H}$ bonds. Absorption peaks at $1,845 \mathrm{~cm}^{-1}$, broad band between $1,650 \mathrm{~cm}^{-1}$ to $1,800 \mathrm{~cm}^{-1}$ and peak at $1,542 \mathrm{~cm}^{-1}$ indicates the $\mathrm{C}-\mathrm{H}_{2}$ bond stretching. The $\mathrm{C}-\mathrm{C}$ bond stretching and $\mathrm{C}-\mathrm{H}$ aliphatic bond bending overlaps at peak between $1,000 \mathrm{~cm}^{-1}$ to $1,400 \mathrm{~cm}^{-1} .25,26$ There were no new bonds detected as can be seen by comparing IR spectra in Figures 3(a), 3(b) and 3(c), which proves that there were no chemical reaction between PVC and NBR.

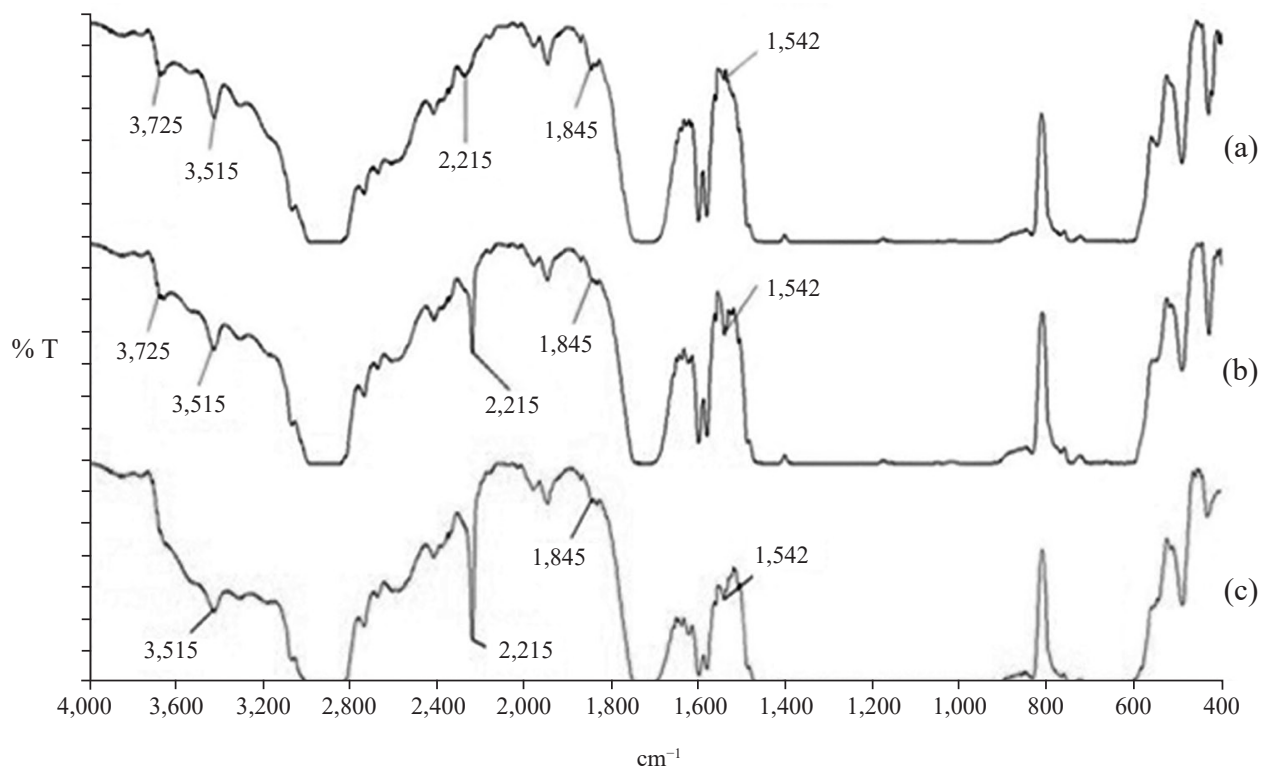

Figure 3: IR spectrum of (a) PVC, (b) PVC/10NBR and (c) PVC/30NBR composites. 
Furthermore, the effect of GO addition on the characteristics of $\mathrm{PVC} /$ NBR composites can be seen by comparing the IR spectra of PVC/NBR and PVC/NBR-GO. The presence of GO in PVC/NBR-GO composite can be confirmed with the presence of absorption peak at $1,588 \mathrm{~cm}^{-1}$ corresponding to the unoxidised $\mathrm{sp}^{2} \mathrm{C}=\mathrm{C}$ bonds in $\mathrm{GO}$ (as shown in Figure 4). Meanwhile, all the absorption peaks from PVC/30NBR reappears in PVC/30NBR-GO except for peak at $3,515 \mathrm{~cm}^{-1}$ which showed minor transition to $3,509 \mathrm{~cm}^{-1}$ in the presence of GO. The transition can be attributed to the reduction of $\mathrm{OH}$ groups from moisture absorbed by PVC. This observation is in line with the intrinsic properties of $\mathrm{GO}$ which enhances the barrier properties of polymer composites and prevents moisture absorption of PVC/NBR composites. Furthermore, few other low intensity peaks that can be observed in between $1,542 \mathrm{~cm}^{-1}$ to $1,742 \mathrm{~cm}^{-1}$ in PVC/30NBR composites have disappeared and merged into a single absorption peak at $1,588 \mathrm{~cm}^{-1}$ in PVC/30NBR-GO composite. This transition can be attributed by the bending or stretching of $\mathrm{CH}_{2}-$ bonds of $\mathrm{PVC}$ in the presence of $\mathrm{GO}$ particles.

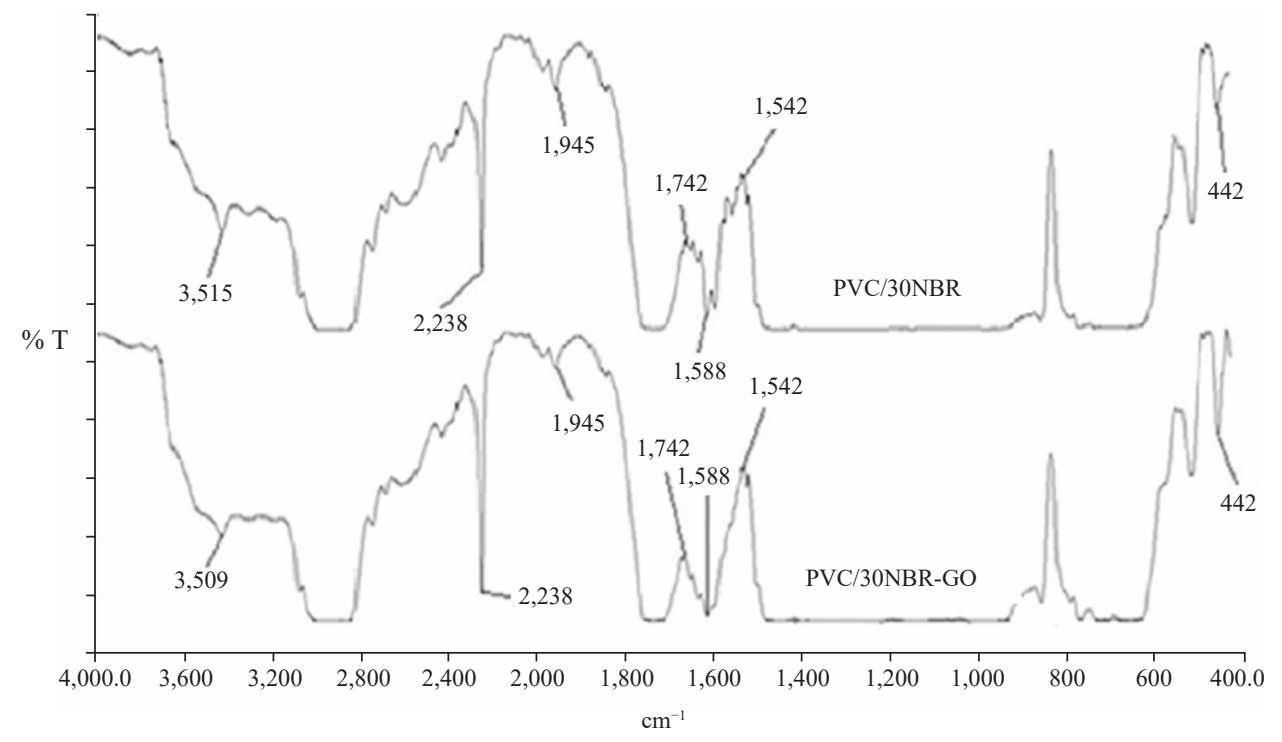

Figure 4: IR spectrum for PVC/30NBR and PVC/30NBR-GO composites.

\subsection{Swelling Resistance}

Swelling test was performed to compare the effect of NBR and NBR-GO addition on the swelling resistance of PVC composites on toluene. Higher swelling percentage indicates low swelling and barrier properties of composites and depicts the low crosslink density of NBR. Both PVC and NBR has poor swelling 
resistance towards toluene, however the moulded composites swells only to a limited extent due to good interfacial adhesion between PVC and NBR. ${ }^{27}$ Both PVC and NBR is a polar material that possess high miscibility and thus both the phases are compatible to each other and tend to adhere strongly. Swelling percentage of PVC was decreased with the addition of NBR and NBR-GO as shown in Figure 5. This result was expected since the composites showed higher mixing torque reading, which can be considered as proportional to the enhancement in interfacial adhesion and having a better mixing between NBR and PVC. Swelling percentage can be related to the presence of interfacial adhesion due to the dispersion of NBR and NBR-GO in PVC. It can be observed from Figure 5, that the swelling percentage was decreased with the addition of $10 \mathrm{wt} . \%$ and $30 \mathrm{wt}$. $\%$ NBR onto PVC. Good interfacial adhesion between PVC and NBR and the presence of cross-linked NBR attribute to the enhanced swelling resistance of PVC/ NBR as compared to PVC. However, the swelling percentage of PVC/30NBR is higher than PVC/10NBR composite. SEM morphological observation revealed that micro-cracks were formed on the surface of PVC/30NBR composites which results in the composite to absorb more toluene as compared to PVC/10NBR. ${ }^{28}$

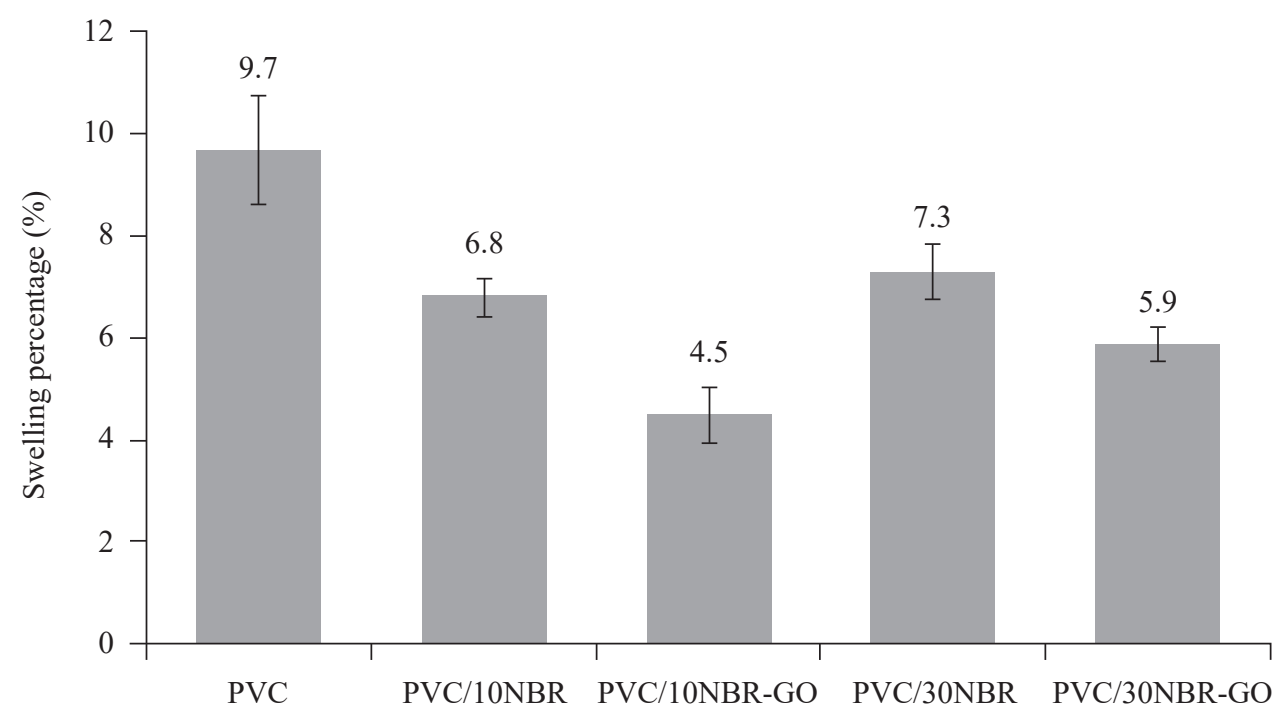

Figure 5: Swelling percentage of PVC, PVC/NBR and PVC-NBR/GO composites.

Meanwhile, the presence of GO in NBR enhances the interfacial adhesion between NBR-GO and PVC and, increased the dispersion of NBRGO in PVC. SEM morphological observation revealed that PVC and NBR-GO formed homogeneous phase at $10 \mathrm{wt}$ \% NBR-GO, and no micro-crack formation at 30 wt. \% NBR-GO. This observation proves greater barrier properties of 
PVC/NBR-GO as compared to PVC/NBR composites which hinders the solvent penetration and results in higher swelling resistance of $\mathrm{PVC} / \mathrm{NBR}-\mathrm{GO}$ composites as compared to neat PVC and PVC/NBR composites.

\subsection{Tensile Properties}

Figure 6 shows the TS results of PVC, PVC/NBR and PVC/NBR-GO composites at different NBR and NBR-GO loadings. TS of PVC/NBR and PVC/NBR-GO composites were recorded to be higher than that of neat PVC. The addition of NBR into PVC promotes rubbery behaviour and the tougher NBR phase can resist more stress as compared to PVC, thus increasing ultimate TS of PVC/NBR and PVC/NBR-GO composites. Good miscibility between PVC and NBR promotes strong interfacial adhesion and stress transfer between the phases allowing the composite to experience high stress loading upon failure. Good miscibility between PVC and NBR results in good wetting of PVC matrix on the NBR phase. Good wetting between the phases then promote efficient stress transfer from PVC to NBR upon stress application. ${ }^{27}$ The optimum TS was obtained with the addition of 10 wt. \% NBR-GO into PVC which is attributed by the strong interfacial adhesion due to good miscibility between PVC and NBR-GO. Besides, the presence of GO in NBR further reinforces the composite system and allows the composite to withstand higher stress as compared to the rest of the composites.

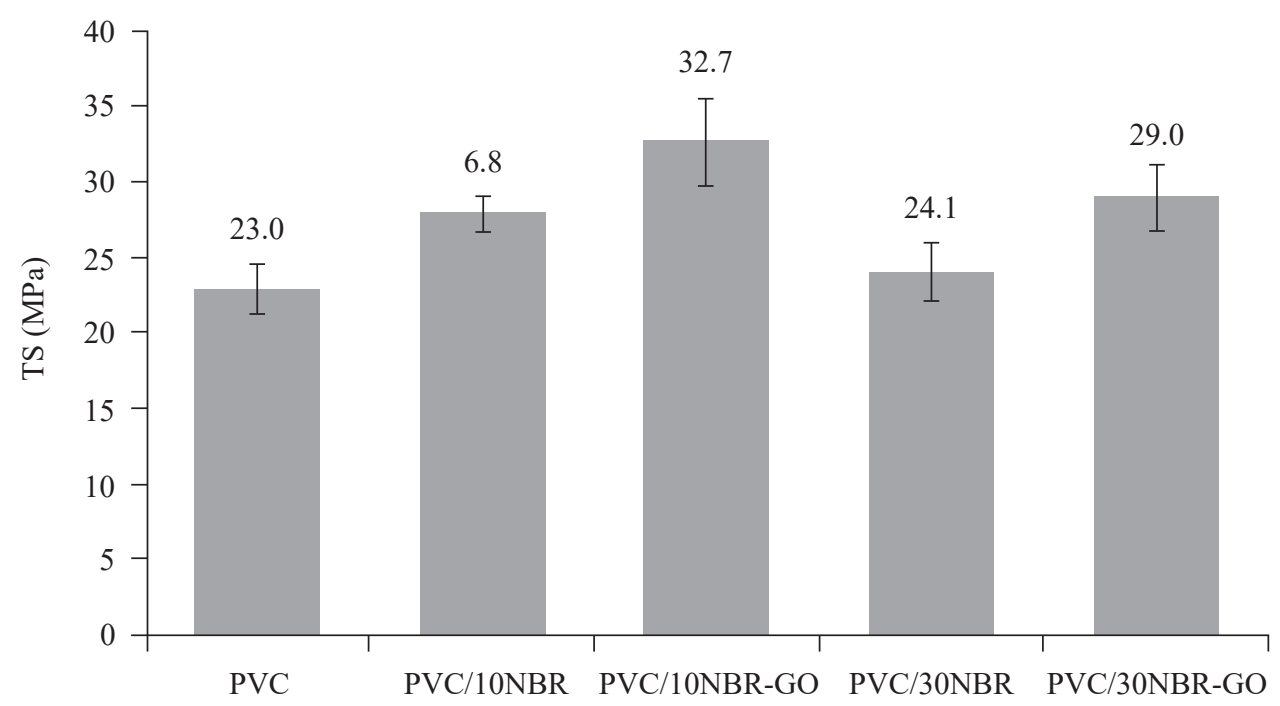

Figure 6: TS of PVC, PVC/NBR and PVC/NBR-GO composites. 
Addition of 10 wt. \% of NBR and NBR-GO increased the TS of the composites as compared to neat PVC. Strong interfacial adhesion and good miscibility between PVC and NBR or NBR-GO promotes efficient stress transfer between the phases and allows the composites to withstand higher stress as compared to neat PVC. Further increasing NBR and NBR-GO loading to $30 \mathrm{wt}$. $\%$ decreases the TS of the composites. Formation of micro-cracks due to phase separation between PVC and NBR or NBR-GO is responsible for the reduction on TS of the composites which is proven through SEM observation as shown in the next section. This result is in line with the reduction of swelling resistance of PVC/30NBR and PVC/30NBR-GO as compared to PVC/10NBR and PVC/10NBR-GO composites.

Theoretically, increasing NBR loading would show a positive improvement on the TS of composite system. However excess loading of NBR above the optimum content attribute to over-curing of NBR due to heat build-up upon mixing. Over-curing occurs due to high shear exerted by internal mixer to ensure homogeneous mixing of the rubbery NBR in PVC. High shear results in heat buildup and the temperature of the mixing column exceeds the maximum processing temperature, resulting in over-curing of NBR and decomposition of PVC phase. Based on the past researches, degraded polymer poses high stiffness which results in low ultimate TS and high modulus of polymer composites. ${ }^{29}$ Results of this research finding is also in line with the past reports by which increasing NBR content above 10 wt. \% NBR decreased the TS of PVC/NBR composites.

Meanwhile by comparing the TS of PVC/NBR and PVC/NBR-GO composites, it was clear that addition of $1 \mathrm{wt}$. \% GO into NBR have further improved the TS of PVC composite. Homogeneous dispersion of NBR-GO in PVC was observed under SEM confirming that GO promotes the dispersion of NBR in PVC at 10 wt. \% NBR-GO loading. Meanwhile increasing NBR-GO loading to 30 wt. \% results in phase separation of $\mathrm{NBR}$ and $\mathrm{PVC}$, which is the reason for low TS of PVC/30NBR-GO as compared to PVC/10NBR-GO composites. GO is a good thermal conductor which can absorb heat and act as filler to further enhance the TS and retain the elasticity of NBR-GO in PVC. High thermal properties of GO allow the particles to absorb the heat build-up created during the shear mixing process in internal mixer. Thus the mixing torque is not affected much due to heat build-up and this prevents the blending material to be more stable. This also prevents the NBR phase not to be over cured and become rigid due to heat buildup. Thus, PVC composites containing NBR-GO showed higher TS as compared to neat PVC and PVC/NBR composites. 
Figure 7 depicts the tensile modulus (E-Mod) of PVC, PVC/NBR and PVC/NBR-GO composites at various NBR and NBR-GO loading. PVC in general is a stiff polymer which is hard to be processed and require the addition of plasticisers as processing aid which reduce the stiffness of the final PVC products. However, high E-Mod of polymer composites is important for dimensional stability as well as to produce a high-performance product which can withstand high strength and impact in wear and tear conditions. As depicted in Figure 7, addition of NBR and NBR-GO improves the E-Mod of PVC composites attributed by the addition of more elastic NBR phase into PVC. NBR is elastic and tough material which has a higher E-Mod in comparison to PVC, thus addition of NBR directly increased the stiffness and E-Mod of the composite. This result is also in line with the higher torque values of PVC/NBR and PVC/NBR-GO composites as compared to neat PVC which indicates high elasticity of the composites with the addition of NBR and NBR-GO. Increasing NBR and NBR-GO loading introduces more elastic phase, subsequently increased the E-Mod of the composites accordingly.

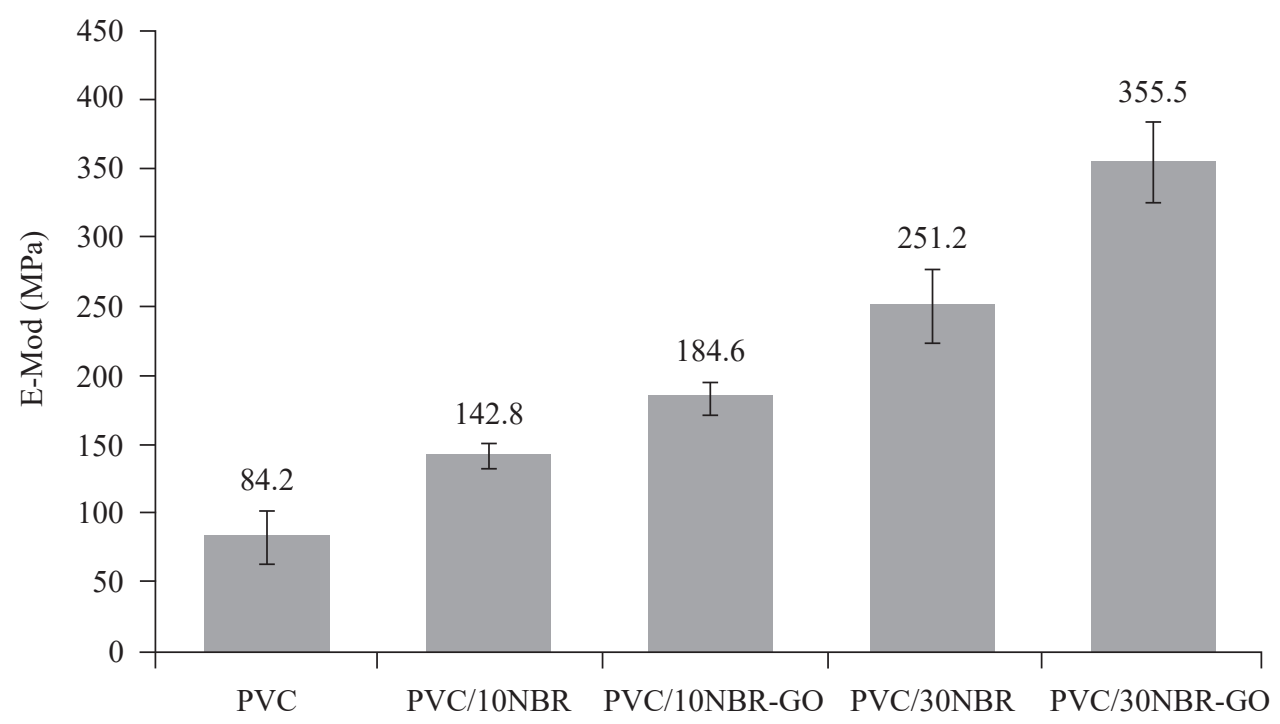

Figure 7: E-Mod of PVC, PVC/NBR and PVC/NBR-GO.

$\mathrm{Eb}$ of PVC composites at different NBR and NBR-GO loadings is shown in Figure 8. The values of Eb of PVC/NBR and PVC/NBR-GO composites are lower as compared to neat PVC. Similar results were reported by Mansour ${ }^{30}$ on the reduction of $\mathrm{Eb}$ of $\mathrm{PVC} / \mathrm{NBR}$ composites with the addition of graphite which is due to the increasing strain resistivity of PVC/NBR with the increasing graphite loading. 
In addition, increasing NBR and NBR-GO loading in PVC further decreased the $\mathrm{Eb}$ of the composites. This result is in good agreement with the increasing E-Mod of PVC with the addition of NBR and NBR-GO, which indicate the reduction of flexibility of PVC/NBR and PVC/NBR-GO composites as compared to neat PVC. However, NBR-GO addition showed low reduction on Eb as compared to NBR and this might be due to good dispersion of NBR-GO in PVC which allows efficient stress transfer in between PVC and NBR-GO and the composites experience larger elongation before fracture as compared to PVC/NBR. Furthermore, the presence of micro-cracks on the surface of PVC/30NBR also proves that the composite has low tensile properties and breaks at low elongation.

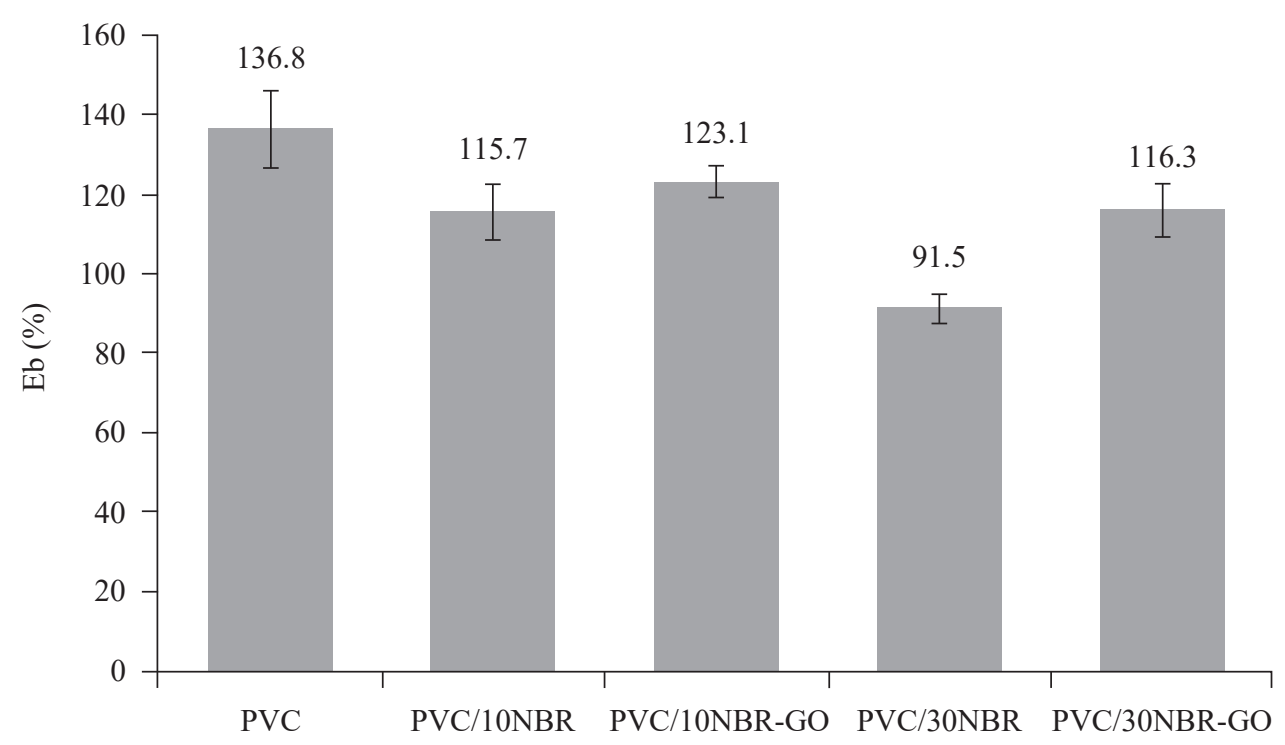

Figure 8: Eb of PVC, PVC/NBR and PVC/NBR-GO.

\subsection{Impact Properties}

Impact test was carried out to determine the impact strength of composite materials by imposing destructive force of $7.5 \mathrm{~J}$ and $15 \mathrm{~J}$ on all the samples. Neat PVC and the composites did not break under the initial impact load of $7.5 \mathrm{~J}$. Figure 9 illustrates the impact strength of the composites under impact load of $15 \mathrm{~J}$. Impact strength of PVC was increased with the addition of $10 \mathrm{wt} . \%$ and $30 \mathrm{wt} . \%$ of NBR and NBR-GO loadings. However, the optimum impact strength was achieved with the addition of 10 wt. \% NBR-GO. Further addition of 30 wt. \% NBR and NBR-GO showed slight reduction in impact strength of the composites. The enhancement of impact strength of PVC with the addition of NBR and NBR-GO 
showed similar trend with the enhancement of TS of the same composites. Good miscibility between PVC and NBR and the presence of GO as filler to reinforce the properties of NBR in PVC allows PVC/NBR-GO composites to withstand higher impact energy as compared to neat PVC and PVC/NBR composites. Similarly, at higher NBR and NBR-GO loading, impact strength of the composite was reduced as compared to $10 \mathrm{wt} \%$ NBR and NBR-GO loading. Over-curing of NBR due to heat build-up upon mixing resulted in NBR to lose its elasticity and ability to withstand high impact energy. Thus, impact strength of PVC containing $30 \mathrm{wt}$. \% NBR and NBR-GO is lower than 10 wt. \% NBR and NBR-GO, respectively.

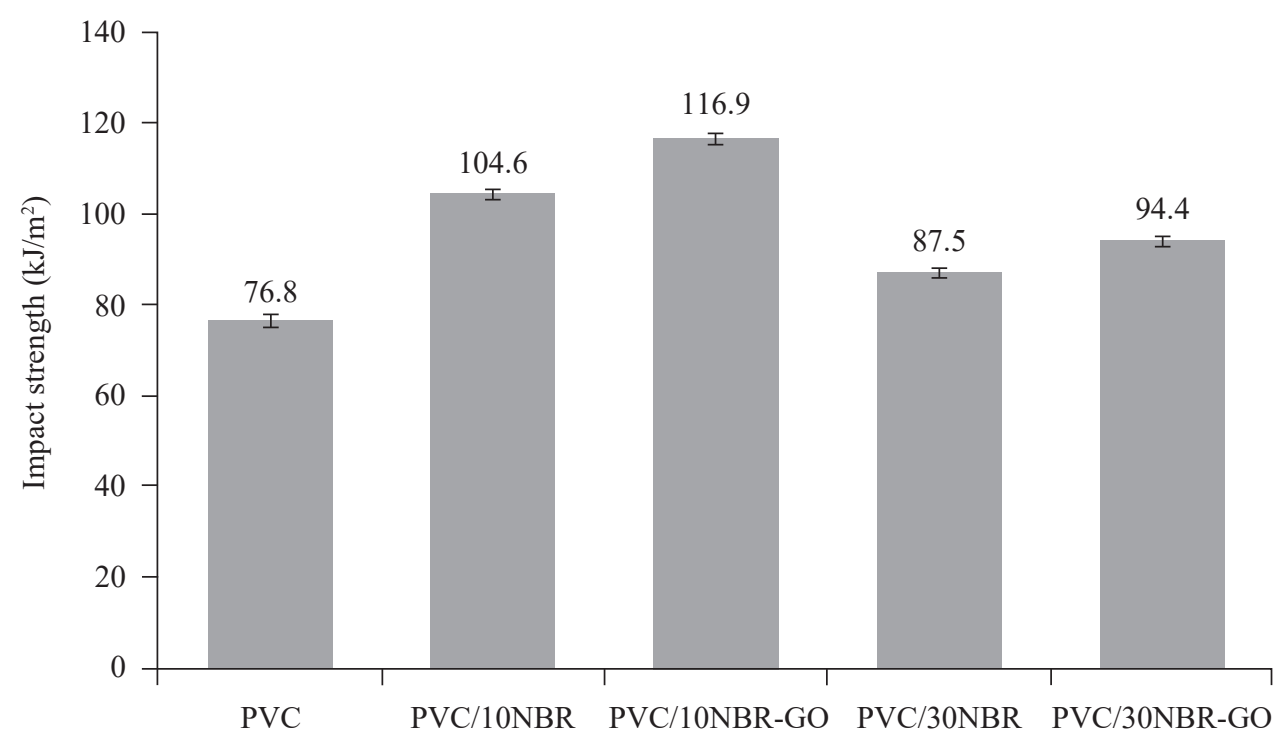

Figure 9: Impact strength of PVC, PVC/NBR and PVC/NBR-GO composites.

\subsection{Morphological Observation}

Under SEM morphological observation, the surface roughness of fracture surface, matrix tearing, interfacial adhesion between PVC and NBR or NBR-GO, and the dispersion of NBR and NBR-GO in PVC was analysed. Surface roughness and matrix tearing on the fracture surface can be used to speculate the resistance of materials to crack propagation as well as the strength of the materials. In general, morphology with high surface roughness and matrix tearing is said to have a high resistance towards crack propagation which allows the materials to deform and withstand higher stress. Figures 10(a) to 10(e) and 11(a) to 11(e) show the surface morphology of the tensile fractured surface of PVC, PVC/NBR and PVC/NBR-GO composites observed under SEM at different magnification. From Figures 10(a) 
and 11(a), which represent the SEM micrographs of tensile fractured surfaces of neat PVC, the fracture results a smooth fracture surface with little matrix tearing. This type of smooth fracture surface indicates very low strength of PVC which is reflected by low resistance towards crack propagation and PVC fractured at low stress application.

Meanwhile, with the addition of 10 wt. \% NBR into PVC, the surface roughness of the composite was increased, and strong matrix tearing can be observed. Good adhesion between PVC and NBR can be seen in Figures 10(b) and 11(b) (white circles) which indicate high resistance of the matrix to applied load which are responsible for the higher strength of PVC/10NBR as compared to PVC. Meanwhile, Figures 10(c) and 11(c) show the SEM observation of PVC/30NBR composite which proves the deterioration of the composite properties were due to the formation of micro-cracks. The cracks are resulted from over-curing of NBR phase which creates rigid phase and decomposed PVC at high processing temperature. ${ }^{31}$ This observation supports the low TS, Eb, swelling resistance and impact strength of PVC/30NBR as compared to PVC/10NBR composite.

On the other hand, the fracture surface of PVC/10NBR-GO composites as shown in Figures 10(d) and 11(d) were seen to have rougher and higher matrix tearing as compared to the surface of PVC and PVC/10NBR composites. This observation suggests that PVC/10NBR-GO able to withstand higher stress as compared to neat PVC and PVC/10NBR composite. Besides, NBR-GO particles were seen to be completely miscible in PVC as there were no phase separation between NBR-GO and PVC. Traces of GO (black spots) can be seen which indicate good dispersion and interfacial adhesion between NBR-GO and PVC. Good miscibility and the presence of $\mathrm{GO}$ results in enhanced properties of $\mathrm{PVC} / 10 \mathrm{NBR}-$ $\mathrm{GO}$ as compared to neat PVC and PVC/10NBR composites.

Meanwhile further increasing of NBR-GO loading to $30 \mathrm{wt} . \%$ results in slight deterioration of the properties of PVC/30NBR-GO composite as compared to PVC/10NBR-GO composite. From Figures 10(e) and 11(e), the fracture surface of PVC/30NBR-GO appeared to be smoother than PVC/10NBR-GO and the matrix tearing was significantly reduced. Besides, chunks of NBR-GO can be seen which shows the phase separation between PVC and NBR-GO at higher loading. Thus, poor dispersion of NBR-GO at higher loading might be the reason for the property's deterioration of PVC/30NBR-GO composite. Besides, no micro-cracks were seen on the fracture surface of PVC/30NBR-GO which supports higher tensile properties, swelling resistance and impact strength of PVC/30NBR-GO as compared to PVC/30NBR composite. 

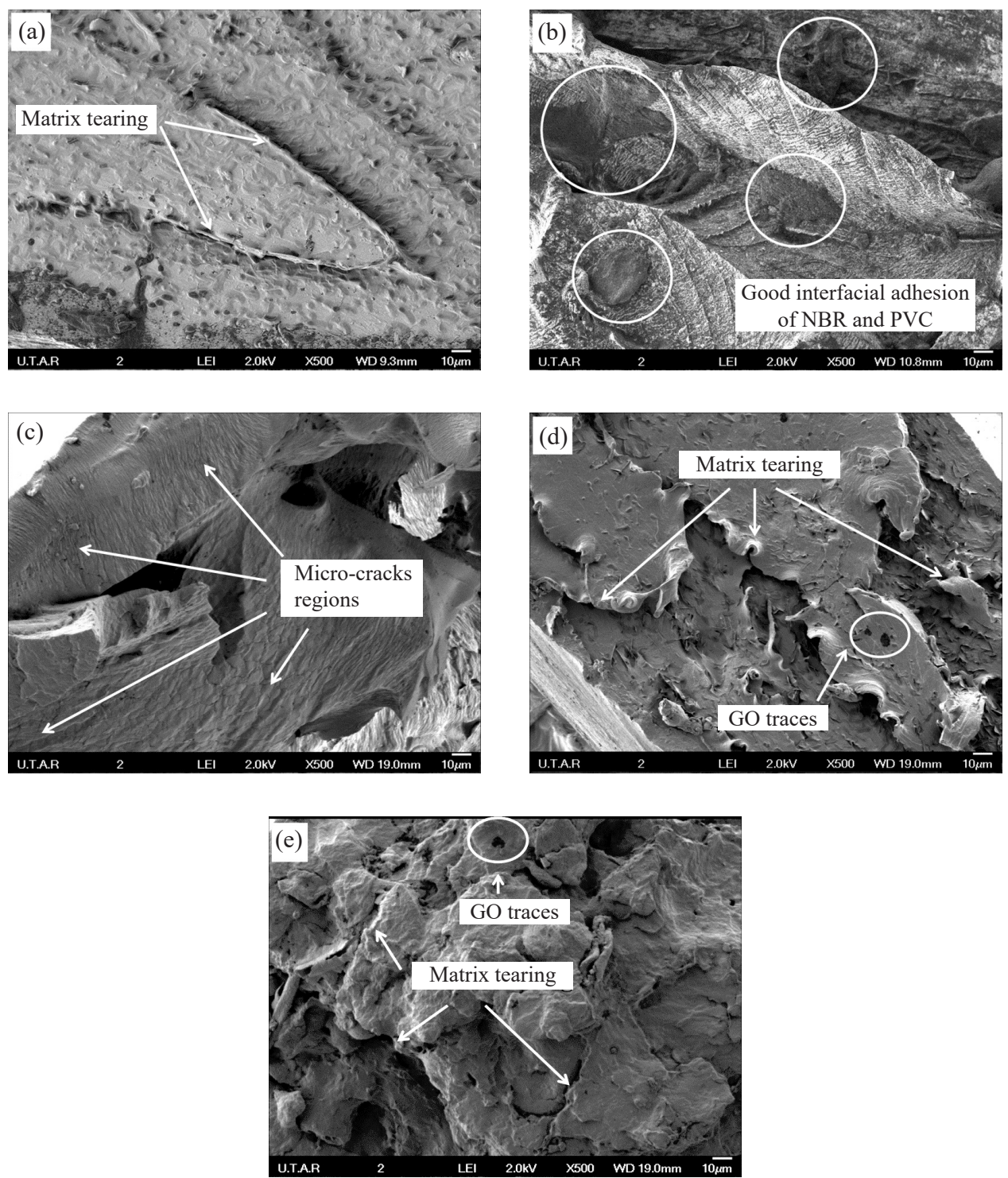

Figure 10: SEM images of (a) PVC, (b) PVC/10NBR, (c) PVC/30NBR, (d) PVC/10NBR$\mathrm{GO}$ and (e) PVC/30NBR-GO composites at $\times 500$ magnification. 

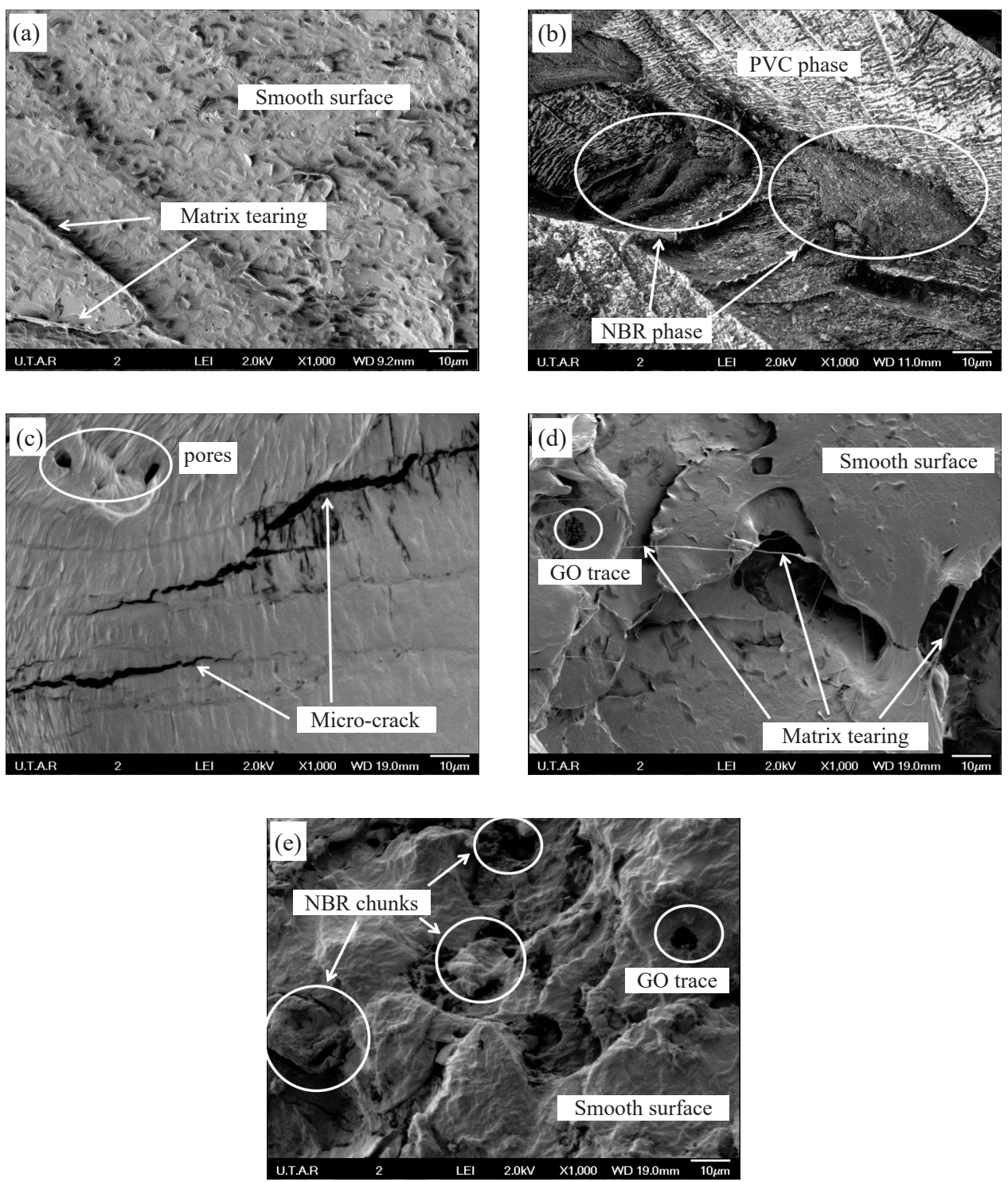

Figure 11: SEM images of (a) PVC, (b) PVC/10NBR, (c) PVC/30NBR, (d) PVC/10NBR$\mathrm{GO}$ and (e) PVC/30NBR-GO composites at $\times 1,000$ magnification. 


\section{CONCLUSION}

NBR and NBR-GO compounds were successfully prepared through latex compounding method using sulphur as curing agents. Addition of $10 \mathrm{wt} . \%$ and 30 wt. \% of NBR and NBR-GO into PVC showed positive improvement in TS, E-Mod, swelling resistance and impact strength of the composites. However, NBR and NBR-GO addition results in higher processing torque and low Eb of the composites. The optimum properties were achieved with the addition of 10 wt. \% NBR-GO which is attributed by good miscibility and dispersion of 10 wt. \% NBR-GO in PVC, as well as good interfacial adhesion between NBR-GO and PVC. Besides, GO particles acts as good thermal conductor and filler in PVC/ NBR blending which further enhances the properties of PVC/NBR composites. Morphological observation revealed that at $30 \mathrm{wt}$ \% NBR and NBR-GO loading, micro-cracks and phase separation occurred resulting in low composite properties as compared to the optimum loading.

\section{ACKNOWLEDGEMENTS}

Authors would like to thank Universiti Tunku Abdul Rahman, Perak, Malaysia for providing required laboratory facilities for successful completion of this research work. Material contributions from Platinum Senawang Sdn. Bhd., Negeri Sembilan, Malaysia and HVW Technologies Pte Ltd., Robinson Road, Singapore are gratefully acknowledged.

\section{REFERENCES}

1. Rai, S., Bhujel, R. \& Swain, B. P. (2018). Electrochemical analysis of graphene oxide and reduced graphene oxide for super capacitor applications. In 2018 IEEE electron devices Kolkata conference (EDKCON). Kolkata, India: IEEE (Institute of Electrical and Electronics Engineers), 489, https://doi.org/10.1109/EDKCON.2018.8770433.

2. Tran, M. H., Yang, C. S., Yang, S., Kim, I. J. \& Jeong, H. K. (2014). Influence of graphite size on the synthesis and reduction of graphite oxides. Curr. Appl. Phys., 14(Supp. 1), 74-79, https://doi.org/10.1016/ j.cap.2013.11.038.

3. Galpaya, D., Wang, M., Liu, M., Motta, N., Waclawik, E. \& Yan, C. (2013). Recent advances in fabrication and characterization of graphenepolymer nanocomposites. Graphene, 1(2), 30-49, https://doi.org/10.4236/ graphene.2012.12005. 
4. Novoselov, K. S., Geim, A. K., Morozov, S. V., Jiang, D., Zhang, Y., Dubonos, S. V., Grigorieva, I. V. \& Firsov, A. A. (2004). Electric field effect in atomically thin carbon films. Science, 306(5696), 666-669, https://doi.org/10.1126/science.1102896.

5. Lai, D., Chen, W. \& Jiang, G. (2013). Research progress of graphenebased composite materials. Curr. Phys. Chem., 3(3), 269-282, https://doi .org/10.2174/1877946811303030004.

6. Nadiv, R., Shtein, M., Buzaglo, M., Peretz-Damari, S., Kovalchuk, A., Wang, T., Tour, J. M. \& Regev, O. (2016). Graphene nanoribbon-polymer composites: The critical role of edge functionalization. Carbon, 99, 444450, https://doi.org/10.1016/j.carbon.2015.12.039.

7. Fim, F. D. C., Basso, N. R. S., Graebin, A. P., Azambuja, D. S. \& Galland, G. B. (2013). Thermal, electrical and mechanical properties of polyethylenegraphene nanocomposites obtained by in situ polymerization. J. Appl. Polym. Sci., 128, 2630-2637, https://doi.org/10.1002/app.38317

8. Wu, X., Liu, S., Cui, X., Lin, J., Zhang, H., Zhang, J. \& Wang. J. (2020). Manipulating microenvironments of nanochannels in lamellar membranes by quantum dots for highly enhanced nanofiltration performance. Chem. Eng. Sci., 228, 116001, https://doi.org/10.1016/j.ces.2020.116001.

9. Shehzad, F., Daud, M. \& Al-Harthi, M. A. (2016). Synthesis, characterization and crystallization kinetics of nanocomposites prepared by in situ polymerisation of ethylene and graphene. J. Therm. Anal. Calorim., 123, 1501-1511, https://doi.org/10.1007/s10973-015-5087-x.

10. Kim, I. H. \& Jeong, Y. G. (2010). Polylactide/exfoliated graphite nanocomposites with enhanced thermal stability, mechanical modulus, and electrical conductivity. J. Polym. Sci. B Polym. Phys., 48(8), 850-858, https://doi.org/10.1002/polb.21956.

11. Jiang, X. \& Drzal, L. T. (2010). Multifunctional high density polyethylene nanocomposites produced by incorporation of exfoliated graphite nanoplatelets 1: Morphology and mechanical properties. Polym. Compos., 31(6), 1091-1098, https://doi.org/10.1002/pc.20896.

12. Alateyah, A. I. (2018). Thermal properties and morphology of polypropylene based on exfoliated graphite nanoplatelets/nanomagnesium oxide. Open Eng., 8(1), 432-439, https://doi.org/10.1515/eng-2018-0052.

13. Woo, J. \& Park, S. (2016). Polypropylene nanocomposite with polypropylene-grafted graphene. Macromol. Res., 24, 508-514, https://doi .org/10.1007/s13233-016-4067-8.

14. Wang, Y., Qing, Y., Sun, Y., Zhu, M. \& Dong, S. (2020). A study on preparation of modified graphene oxide and flame retardancy of polystyrene composite microspheres. Des. Monomers Polym., 23(1), 1-15, https://doi.org/10.1080/15685551.2020.1720934. 
15. Chen, D., Zhu, H. \& Liu, T. (2010). In situ thermal preparation of polyimide nanocomposite films containing functionalized graphene sheets. ACS Appl. Mater. Interfaces, 2(12), 3702-3708, https://doi.org/ 10.1021/am1008437.

16. Liao, K. H., Kobayashi, S., Kim, H., Abdala, A. A. \& Macosko, C. W. (2014). Influence of functionalized graphene sheets on modulus and glass transition of PMMA. Macromolecules, 47(21), 7674-7676, https://doi. org/10.1021/ma501709g.

17. Graziano, A., Jaffer, S. \& Sain, M. (2019). Review on modification strategies of polyethylene/polypropylene immiscible thermoplastic polymer blends for enhancing their mechanical behavior. J. Elastomers Plast., 51(4), 291-336, https://doi.org/10.1177/0095244318783806.

18. Mousa, A., Ishiaku, U. S. \& Mohd Ishak, Z. A. (2005). The effect of prolonged thermo-oxidative ageing on the mechanical properties of dynamically vulcanized poly (vinyl chloride)/nitrile butadiene rubber thermoplastic elastomers. Int. J. Polym. Mater. Po., 55(4), 235-253, https://doi.org/10.1080/009140390927303.

19. Hajibaba, A., Naderi, G., Esmizadeh, E. \& Ghoreishy, M. H. R. (2014). Morphology and dynamic-mechanical properties of PVC/NBR blends reinforced with two types of nanoparticles. J. Compos. Mater., 48(2), 131-141, https://doi.org/10.1177/0021998312469242.

20. Kaliyathan, A. V., Varghese, K., Nair, A. S. \& Thomas, S. (2020). Rubberrubber blends: A critical review. Prog. Rubber Plast. Recycl., 36(3), 196242, https://doi.org/10.1177/1477760619895002.

21. Wimolmala, E., Wootthikanokkhan, J. \& Sombatsompop, N. (2001). Effects of composition and temperature on extrudate characteristics, morphology, and tensile properties of acrylic rubber-blended PVC. J. Appl. Polym. Sci., 80(13), 2523-2534, https://doi.org/10.1002/app.1361.

22. Wong-on, J. \& Wootthikanokkhan, J. (2003). Dynamic vulcanization of acrylic rubber-blended PVC. J. Appl. Polym. Sci., 88(11), 2657-2663, https://doi.org/10.1002/app.12070.

23. Khalaf, A., Yehia, A., Ismail, M. \& El-Sabbagh, H. (2012). High performance oil resistant rubber. Open J. Org. Polym. Mater., 2, 89-93, https://doi.org/10.4236/ojopm.2012.24013.

24. Sali, S., Mackey, H. R. \& Abdala, A. A. (2019). Effect of graphene oxide synthesis method on properties and performance of polysulfone-graphene oxide mixed matrix membranes. Nanomaterials, 9(5), 769, https://doi .org/10.3390/nano9050769. 
25. Tham, D. Q., Mai, T. T., Hoang, T., Trang, N. T. T., Chinh, N. T. \& Thang, D. X. (2019). Preparation and FTIR studies of PMMA/PVC polymer blends, PVC-g-PMMA graft copolymers and evaluating graft content. Vietnam J. Sci. Technol., 57(1), 48-59, https://doi.org/10.15625/2525 $-2518 / 57 / 1 / 12682$.

26. Xiao, Y., Xin, B., Chen, Z., Lin, L., Liu, Y. \& Hu, Z. (2019). Enhanced thermal properties of graphene-based poly (vinyl chloride) composites. $J$. Ind. Text., 48(8), 1348-1363, https://doi.org/10.1177/1528083718760805.

27. George, K. E., Joseph, R. \& Francis, D. J. (1986). Studies on NBR/PVC blends. J. Appl. Polym. Sci., 32(1), 2867-2873, https://doi.org/10.1002/ app.1986.070320102.

28. Zhang, H., Xing, W., Li, H., Xie, Z., Huang, G. \& Wu, J. (2019). Fundamental researches on graphene/rubber nanocomposites. Advanced Industrial and Engineering Polymer Research, 2(1), 32-41, https://doi .org/10.1016/j.aiepr.2019.01.001.

29. Bhattacharyya, A., Chen, S. \& Zhu, M. (2014). Graphene reinforced ultra high molecular weight polyethylene with improved tensile strength and creep resistance properties. Express Polym. Lett., 8(2), 74-84, https://doi.org/10.3144/expresspolymlett.2014.10.

30. Mansour, S. A. (2008). Effect of extensional cyclic strain on the mechanical and physico-mechanical properties of PVC-NBR/graphite composites. Express Polym. Lett., 2(12), 836-845, https://doi.org/10.3144/ expresspolymlett.2008.98.

31. Möwes, M. M., Fleck, F. \& Klüppel, M. (2014). Effect of filler surface activity and morphology on mechanical and dielectric properties of NBR/Graphene nanocomposites. Rubber Chem. Technol., 87(1), 70-85, https://doi.org/10.5254/rct.13.87930. 